\title{
Identidade de gênero e orientação sexual na escola: Um debate necessário
}

\author{
Gender identity and sexual orientation at school: A necessary debate \\ Identidad de género y orientación sexual en la escuela: Un debate necesario
}

Recebido: 19/07/2021 | Revisado: 23/07/2021 | Aceito: 23/07/2021 | Publicado: 01/08/2021

\author{
Gerson Avelino Fernandes Pereira \\ ORCID: https://orcid.org/0000-0003-0536-5861 \\ Instituto Federal do Norte de Minas Gerais, Brasil \\ E-mail: gerson.pereira@ifnmg.edu.br \\ Gilmara Gonçalves Santos \\ ORCID: https://orcid.org/0000-0002-2617-0134 \\ Instituto Federal do Norte de Minas Gerais, Brasil \\ E-mail: gilmara.santos@ifnmg.edu.br
}

\begin{abstract}
Resumo
A sociedade é marcada por constructos tecidos no decorrer da história e que são incutidos no imaginário social dos sujeitos como legitimadores de uma ordem estabelecida e, quando se propõe debates num itinerário contrário ao normativo, estes são tidos como temas polêmicos. A inclusão da identidade de gênero e orientação sexual como pauta a ser discutida traz consigo esta inquietação, pois involuntariamente mexe com estruturas de pensamento construídas sob a égide de um padrão indiscutível de comportamento sexual e expressão de gênero, mormente quando o lócus de discussão se dá na escola. Nesse sentido, este trabalho tem como temática analisar panoramicamente escritos publicados e legislações que possam subsidiar o debate acerca da identidade de gênero e orientação sexual, principalmente dentro do espaço escolar. Buscou-se fazer um levantamento bibliográfico a partir de fontes e legislações concernentes à área, sem a pretensão de traçar qualquer imposição ideológica que pressuponha um esgotamento do assunto quando este se esbarra em padrões hegemônicos de pensamento. Propôs-se, então, uma pesquisa qualitativa, objetivando retirar da invisibilidade temas como este que carregam o mote central deste trabalho. Assim, pôde-se verificar que o adentrar desta discussão na sociedade e na escola é urgente e necessário e isso só se faz com a abertura ao debate qualificado, na tentativa de retirar a diversidade da invisibilidade e destruir barreiras construídas pela perpetuação de conceitos sociais que se fizeram ao longo do tempo e foram apropriados como sendo verdades imutáveis dentro de uma lógica padrão validada socialmente ao longo dos séculos.
\end{abstract}

Palavras-chave: Identidade de gênero; Orientação sexual; Diversidade.

\begin{abstract}
Society is marked by constructs woven throughout history and which are instilled in the social imagination of subjects as legitimizers of an established order and when debates are proposed in an itinerary contrary to the normative, these are considered controversial themes. The inclusion of gender identity and sexual orientation as an agenda to be discussed brings with it this concern, as it unwittingly interferes with thought structures built under the aegis of an indisputable pattern of sexual behavior and gender expression, especially when the locus of discussion occurs at school. In this sense, this work has as its theme to panoramically analyze published writings and legislation that can support the debate about gender identity and sexual orientation, mainly within the school space. We sought to carry out a bibliographical survey from sources and legislation concerning the area, without intending to trace any ideological imposition that presupposes an exhaustion of the subject when it collides with hegemonic patterns of thought. It was proposed, then, a qualitative research, aiming to remove from invisibility themes like this that carry the central theme of this work. Thus, it could be verified that entering this discussion in society and in school is urgent and necessary and this can only be done with the opening to qualified debate, in an attempt to remove diversity from invisibility and destroy barriers built by the perpetuation of social concepts that were made over time and were appropriated as being immutable truths within a standard logic socially validated over the centuries.
\end{abstract}

Keywords: Gender identity; Sexual orientation; Diversity.

\section{Resumen}

La sociedad está marcada por construcciones tejidas a lo largo de la historia y que se inculcan en el imaginario social de los sujetos como legitimadores de un orden establecido y cuando se proponen debates en un itinerario contrario a lo normativo, estos son considerados como temas controvertidos. La inclusión de la identidad de género y la orientación sexual como guía a discutir trae consigo esta inquietud, porque interfiere involuntariamente en las estructuras de pensamiento construidas bajo la égida de un patrón indiscutible de comportamiento sexual y expresión de género, especialmente cuando el lugar de discusión tiene lugar en la escuela. En este sentido, este trabajo tiene como objetivo analizar escritos y legislaciones publicadas panorámicamente que puedan apoyar el debate sobre la identidad de género 
y la orientación sexual, especialmente dentro del espacio escolar. Se buscó realizar un estudio bibliográfico de fuentes y legislación sobre el área, sin la intención de rastrear ninguna imposición ideológica que presuponía un agotamiento del sujeto cuando se enfrenta a patrones hegemónicos de pensamiento. Se propuso, entonces, una investigación cualitativa, con el objetivo de eliminar de la invisibilidad temas como este que llevan el tema central de este trabajo. Así, se pudo comprobar que la admisión de esta discusión en la sociedad y en la escuela es urgente y necesaria y esto sólo se hace con la apertura al debate calificado, en un intento de eliminar la diversidad de la invisibilidad y destruir las barreras construidas por la perpetuación de conceptos sociales que se han hecho a lo largo del tiempo y fueron apropiados como verdades inmutables dentro de una lógica estándar socialmente validada a lo largo de los siglos.

Palabras clave: Identidad de género; Orientación sexual; Diversidad.

\section{Introdução}

O presente artigo desenvolveu-se na perspectiva de deslindar questões concernentes às temáticas de gênero e orientação sexual em discussão hodiernamente na mídia, nos meios de disseminação de informações e na escola enquanto espaço de construção de saberes.

A polemicidade dessas temáticas hoje perpassa construções sociais que se estabeleceram ao longo de anos como hegemônicas e incontestáveis, tanto por envolver questões de cunho religioso quanto ideológicas, e a escola como meio de reprodução de filosofias dominantes de seus aparelhos mantenedores acaba se sucumbindo a não promover esse tipo de discussão.

Nesse sentido, temas com certo grau de profundidade de discussão devem ser abarcados pela escola, num exercício de autonomia e de empoderamento, diante dos vários entreveros sociais que se impuseram diante desta num intento de inferiorizála no que diz respeito ao seu aspecto formativo e identitário de sujeitos.

Sendo assim, identidade de gênero e orientação social se fazem necessárias na escola como ponto de discussão e mecanismo de desfazimento de ideias segregadoras de seres humanos na sociedade, bem como, auxiliar no entendimento de que a diversidade existe e ela se aplica ao ser humano em todas as suas nuances.

Dessa forma, a opção por discutir de forma panorâmica a temática supracitada, se dá no intuito de retirar da adjacência a questão do deslindamento da orientação sexual e identidade de gênero como possuidoras de significações diferentes e que, pela maioria das vezes, se confundem tanto a senso comum como na área acadêmica e em espaços formais de educação. Assim, com esse estudo de desenvolvimento teórico, pretende-se buscar na literatura e legislações algumas elucidações a respeito de gênero e orientação sexual dentro do ambiente escolar que possam levantar pontos importantes para a discussão desses conceitos dentro da escola, promovendo esse debate que é necessário.

Cabe iniciar uma discussão sem pretensão de completude e com plena consciência da incipiência de temas como esse dentro do ambiente escolar e para tal foi realizado um estudo panorâmico de levantamento bibliográfico, sem qualquer pretensão de esgotar-se no mesmo, configurando uma tentativa preambular de trazer à baila essa discussão tão necessária.

\section{Metodologia}

Este artigo teve como trilha metodológica um levantamento bibliográfico, redesenhando as óticas atuais sobre a temática deslindada, trazendo à tona contribuições de escritos publicados em áreas correlatas e legislações que puderam embasar o debate e oferecer uma nova roupagem a respeito do assunto abordado, no intuito de ascender alguns questionamentos necessários.

Severino (2007, p. 122), esclarece que levantamento bibliográfico é aquele que "[...] se realiza a partir do registro disponível, decorrente de pesquisas anteriores, em documentos impressos, como livros, artigos, teses, etc. [...] Os textos tornamse fontes dos temas a serem pesquisados."

Quanto à abordagem optou-se pela qualitativa. Esta “[...] se refere ao fato de que não se pode insistir em procedimento [sic] sistemáticos que possam ser previstos, em passos ou sucessões como uma escada em direção à generalização" (Martins, 
2010, p. 63), dispensando assim procedimentos estáticos e quantitativos e não se configura "como uma proposta rigidamente estruturada, ela permite que a imaginação e a criatividade levem os investigadores a propor trabalhos que explorem novos enfoques." (Godoy, 1995, p. 21).

\section{Resultados e Discussão}

As discussões a respeito de Gênero e sexualidade dentro da escola têm sido cada vez mais polidas por políticas castradoras e certamente simpatizantes de uma ideologia dominante, em que, o objetivo se traduz em promover esse alijamento cada vez maior de temas necessários à construção do ser humano a partir de sua existência.

A concepção de ser humano segundo Guareschi $(2008$, p. 6) se dá:

[...] não como algo pronto, mas como em contínua construção. Ser humano significa, de fato, tornar-se humano, conquistar-se. A subjetividade humana é o resultado de milhões de relações. Recortamos, do universo dos milhares e milhões de relações que estabelecemos, parcelas específicas, diferenciadas e, com isso, construímos nossa subjetividade. Por isso mesmo, somos absolutamente singulares, únicos, irrepetíveis, pessoais (pessoa = relação).

Destarte, pode-se observar que, enquanto indivíduos habitantes desse universo, somos construídos e reconstruídos a partir de relações, e assim a exatidão do ser e seus retoques finais nunca estão prontos e chancelados, pois cada ponto de chegada é também ponto de partida para um novo aperfeiçoamento e a travessia entre esses extremos do caminho precisa ser valorizada como processo, pois é aí que o real se dispõe para nós enquanto sujeitos (Rosa, 2019).

Falar de ser humano traz consigo a necessidade de discutir também sobre como este se identifica socialmente e como se coloca perante o lugar que às vezes é até mesmo imposto por ideologias dominantes, que já perpetuaram por muito tempo e acabam sendo concebidas como detentoras da verdade absoluta, dessa forma, não há como não iniciar algumas provocações sobre gênero.

Guedes (1995, p.11) na década de 90 do século XX já nos convidava a pensar "assim, em lugar de nos perguntarmos sobre o que é Gênero ou Gênero, o que é isso? será que não deveríamos buscar a compreensão de como esta denominação está se Construindo/Desconstruindo?. A partir dessa premissa, é possível pensar já no prelúdio dessa discussão, o quão necessária se faz a quebra de tabus em relação a essa temática e a condução do debate na direção do caráter social que envolve este conceito e sua abstenção de explicar-se através de discursos simplistas e reducionistas.

Nesse sentido Butler (2003, p. 37) corrobora que:

O gênero é uma complexidade cuja totalidade é permanentemente protelada, jamais plenamente exibida em qualquer conjuntura considerada. Uma coalizão aberta, portanto, afirmaria identidades alternativamente instituídas e abandonadas, segundo as propostas em curso; tratar-se-á de uma assembléia que permita múltiplas convergências e divergências, sem obediência a um telos normativo e definidor.

A construção das significações necessárias ao campo do gênero, a partir das autoras supracitadas, se percebe por demais complexa e carregada de multiplicidade dentro do âmbito social, pois não são distantes as correntes de pensamento que vulgarizam o discurso a partir de referenciais pessoais baseados em senso comum ou dogmas religiosos, na tentativa de anular o viés social que está imbuído na tessitura dos conceitos.

Na escola, não é diferente, pois, por mais que tenhamos um ambiente laico garantido pela Constituição Federal (1988) através da interpretação clara do seu artigo 19, na prática, o que se percebe é o embate entre arcabouços culturais e perspectivas religiosas divergentes, que na maioria das vezes, sucumbe a discussão qualificada de temas importantes para a formação dos sujeitos na perspectiva da convivência parcimoniosa entre os diversos pontos de vista e lugares de fala. 
Libâneo, Oliveira e Toschi (2012, p. 412) trazem uma perspectiva diferente, ressaltando que a "escola é uma organização em que tanto seus objetivos e resultados quanto seus processos e meios são relacionados com a formação humana, ganhando relevância, portanto, o fortalecimento das relações sociais, culturais e afetivas que nela têm lugar”, o que nos leva ao entendimento de que, por mais complexos que sejam os processos formativos, devido a pluralidade de concepções de mundo que cada um carrega consigo, a relevância precisa estar direcionada à dimensão humana do indivíduo, na tentativa de construção deste como ser social e suas necessárias desconstruções cotidianas.

A partir dessas provocações, é percebível que a escola é constitutiva de embates, e que, a educação, como processo formal que ali acontece, não se resume à aquisição de conhecimentos vazios, dotados de uma aplicabilidade utilitária em exames de aprovação e quantificadores de saberes, para além disso, dentro da escola, existem debates que são necessários e urgentes, pois dizem da constituição do ser enquanto sujeito e a discussão destes de forma quebrar paradigmas de redução do ser humano a uma binariedade construída socialmente de gênero e orientação sexual se faz de extrema importância.

Mendes e Silva (2020) ao iniciar um estudo de análise espacial dos homicídios da população LGBT no Brasil, interpelam que este é o país que mais registra crimes contra essa população no contexto mundial, e a partir disso torna-se mais evidente a necessidade do recrudescimento de políticas públicas que não só sejam punitivas, mas também guarneçam o debate desse tema na sociedade e principalmente na escola.

A invisibilização de gêneros e sexualidades não normativas não devem passar por um processo social de naturalização, haja vista que "nossa sociedade heterossexista e homofóbica, ao estigmatizar e satanizar os homossexuais [e transgêneros], obriga sua grande maioria a viver enrustidos, inibindo ou proibindo a entrada de casais do mesmo sexo em pensões e motéis [e espaços públicos] [...]." (Mott \& Cerqueira, 2003, p. 38, interpolação nossa).

E nesse processo, o debate escolar é de extrema importância, inclusive dentro dos currículos e planejamentos, para que isso se concretize dentro da sala de aula como um tema transversal. E por falar em transversalidade, segundo Silva, Maraschin, Funari, Mello e Junqueira (2020) o que temos hoje em termos de políticas legais de incentivo a essa discussão é bem escasso e não permitem reflexão, submetendo a educação nacional sempre ao domínio do conservadorismo e preceitos religiosos, que por sua vez marginalizam todo e qualquer sujeito que não esteja dentro de um padrão definido.

Um exemplo disso é a Base Nacional Comum Curricular (2018) que traz consigo um retrocesso em relação a documentos anteriores como a Lei de Diretrizes e Bases da Educação Nacional (1996), que tem como princípio a garantia de "respeito à liberdade e apreço à tolerância" preconizados no seu artigo $2^{\circ} \mathrm{e}$ as Orientações Curriculares Nacionais para o Ensino Médio (2006, p. 220) que preconizam que, "mais que alunos e jovens, eles constroem suas subjetividades e identidades a partir de condições de pertencimento a determinado gênero, etnia, classe social, prática religiosa, orientação sexual, etc. Essas condições de pertencimento, por sua vez, também ajudam na construção desses alunos como sujeitos socioculturais [...].”

Diante dessa temática, Nogueira (2010, p. 14-15), traz uma contribuição relevante ao complementar que "sendo a sexualidade, entendida como uma construção social, histórica e cultural, sente-se a necessidade de ser discutida na escola", mas frisa de forma bastante clara que “[...] a sexualidade é vista de diferentes formas em cada época e em cada povo, pois com a modernidade cada geração tem em mente um novo conceito sobre sexualidade."

A partir dessa contribuição, somos conduzidos a uma linha de raciocínio que permite inferir a plasticidade como sendo um adjetivo pertinente ao campo da sexualidade e do gênero, pois fala-se muito mais de uma construção que se deu ao longo da história com influências culturais, sociais e visões de mundo do que uma designação divina que atribui ao binômio macho-fêmea ou homem-mulher a única forma de expressão de gênero permitida dentro de uma lógica heteronormativa, bem como, a heterossexualidade, como sendo a única orientação sexual existente, correta e ilibada.

Na concepção de Louro (2008, p.18) “a construção do gênero e da sexualidade dá-se ao longo de toda a vida, continuamente, infindavelmente", e ainda corrobora que esse processo se viabiliza 
[...] através de inúmeras aprendizagens e práticas, insinua-se nas mais distintas situações, é empreendida de modo explícito ou dissimulado por um conjunto inesgotável de instâncias sociais e culturais. É um processo minucioso, sutil, sempre inacabado. Família, escola, igreja, instituições legais e médicas mantêm-se, por certo, como instâncias importantes nesse processo constitutivo. (Louro, 2008, p. 18).

Jesus (2012, p.12) promove um salto qualitativo nas discussões até aqui feitas e traz-nos até o ponto chave da problemática proposta quando ressalta que:

Gênero se refere a formas de se identificar e ser identificada como homem ou como mulher. Orientação sexual se refere à atração afetivossexual por alguém de algum/ns gênero/s. Uma dimensão não depende da outra, não há uma norma de orientação sexual em função do gênero das pessoas, assim, nem todo homem e mulher é "naturalmente" heterossexual. (grifo nosso).

A autora acima toca num ponto que é importante minuciar, pois traz uma diferenciação clara e ao mesmo necessária entre gênero e orientação sexual, caracterizando esse contraponto existente entre os dois conceitos que, por vezes são tratados como se fossem sinônimos, seja por ignorância de quem o diz ou até mesmo pela falta de embasamento teórico, que leva a uma sucessão de achismos fundamentados em convenções sociais perpetuadas pelas instâncias hegemônicas. Dessa forma, a discussão de temas polêmicos em ambiente escolar traz inquietações de ordem social e psicológica, uma vez que não se sabe ao certo qual a constituição basilar dos conceitos que sustentam esse embate.

$\mathrm{Na}$ contramão das normativas de padrões sociais que imperam na atualidade e que trazem ao longo de sua trajetória histórica a irrevogabilidade de pseudo-legislações que se firmaram como regras prontas e acabadas, apontamentos sobre identidade de gênero e sexualidade na escola se tornam mecanismos de ruptura contra o silenciamento das vozes que constroem a sociedade heterogênea que se estabelece até a atualidade.

Miskolci (2012, p. 34) alerta, nesse contexto que, "a recusa violenta de formas de expressão de gênero ou sexualidade em desacordo com o padrão é antecedida e até apoiada por um processo educativo heterossexista, ou seja, por um currículo oculto comprometido com a imposição da heterossexualidade compulsória”, e isso nos faz pensar e repensar sobre como se tem dado no âmbito escolar essas discussões que são vitais no constructo do ser humano.

O deslindamento de temas que geram certa inquietação se faz necessário na escola, uma vez que esta segundo Severino (2007) é espaço não só de produção de saberes, mas também de reprodução e sistematização de conhecimentos perpassa também a construção do indivíduo, em todas as suas dimensões, o que adquire sentido nas fronteiras da tessitura do ser humano enquanto sujeito complexo demais para se mostrar reduzido a uma binariedade construída e perpetuada socialmente ao longo dos séculos.

E não poderia ser mais oportuna a consideração de Jacó - Vilela e Sato (2012, p. 164) quando salientam que "[ [...] gênero, sexualidade e gerações constituem dispositivos identitários que engendram discursos de verdade imbricados nos processos de (auto) constituição dos sujeitos".

Nesse sentido algumas considerações são feitas por Silva M. F. R (2014, p.16), quando ela pontua que “[...] a escola/professor lida com questões de gênero e sexualidade no seu cotidiano. [...] é possível observar que as relações de gênero tem sido alvo de ensinamento dos adultos[...] muitos confundem sexo com sexualidade. São concepções diferentes que devem ser esclarecidas pela escola" no sentido de provocar a urgência de se repensar o papel do próprio sujeito na constituição de si mesmo em relação aos seus ideários sobre sexualidade e gênero e qual tem sido o papel da escola ao abarcar esse indivíduo num processo de educação formal, seja em qual nível for.

Dessa forma, Silva (2013, p.20) nos traz uma importante reflexão quando argumenta que:

A sexualidade é uma reflexão que ainda é uma espécie de "tabu" e que remete muito mais o lado "reprodutivo", do "papel da procriação", dos métodos anticoncepcionais, do combate à natalidade, do que propriamente ao exercício de autoconhecimento, do respeito ao outro e da "significação" do que vem a ser "sexo", "sexualidade", "prazer", "HIV", 
"hetero ou homo", "orientação sexual" (conforme reza o PCN), assim como uma infinidade de conceitos que fazem parte do cenário do que conhecemos por "Sexualidade", de maneira ampla. Discutir a sexualidade [e identidade de gênero] é discutir a vida (direito fundamental do ser humano garantido por Lei). (interpolação nossa).

Ao fazer uma análise das ideias da autora acima, pode-se perceber que questões como gênero e sexualidade transcendem o campo do mero formalismo e se encaixam no cenário da reflexão ideológica, uma vez que perpassa as peculiaridades de cada ser dentro de um determinado contexto social, situado historicamente, e nesse exercício de debruçar-se sobre aspectos constituintes da vida e da leitura subjetiva de mundo, corre-se o risco de avalanches conceituais que certamente causam desequilíbrios numa ordem social já perpetuada e hegemonizada com seus próprios conceitos de ser e de comportamento socialmente aceitáveis.

Paralelo às discussões até aqui engendradas, vale salientar que, como espaço de contradição e construção de conhecimento, a escola tende a ser palco dessas discussões polemizadas pelo discurso social castrador que pauperiza o gênero e a sexualidade dentro dos espaços formativos, e a partir desse choque de informações de seu legado antecedente à escola, urge pensar quais seriam as concepções vigentes que esse espaço educativo carrega acerca da inserção da orientação sexual - gênero no discurso e na prática educacional e como esse debate se materializa no cotidiano escolar.

Segundo Pupo (2007, p.4) "precisamos trazer para o interior da escola as reflexões e discussões sobre os papéis que a sociedade atribui a cada sexo para que professoras (es) e alunas(os) descubram as limitações a que estaremos sujeitos se nos submetermos aos estereótipos de gênero. É preciso intervir, explicitar, reconhecer as diferenças [...].”

Destarte, é possível apontar a necessidade da escola de abarcar e tomar para si as provocações sobre gênero e sexualidade, mesmo com as escassas e quase inexistentes legislações normativas que respaldam essas discussões para além da dimensão biológica, cisgênera e heteronormativa, pois o espaço da educação formal também é ambiente de confrontos intelectuais, embates teóricos e rearranjos de saberes, ou seja, nem tudo que se estabelece como vigente na sociedade deve ser abarcado pela escola como verdades a serem reproduzidas, é papel da mesma promover as devidas colisões epistemológicas, e ser não só transmissora, mas construtora de episteme.

Dessa forma, a escola, num exercício de imposição enquanto instituição de formação deve levar em consideração que sua clientela representa as mais variadas nuances de pessoas, raças, sexo, costumes, convergências e discrepâncias e cada um traz consigo não só características, mas para além disso posicionamentos ideológicos, assim, questões que concernem à afetividade, à sexualidade e a identidade de gênero também são trazidas nesse arcabouço pessoal de cada aluno, que por vezes representam as ideologias dominantes na sociedade e por outras não, e nesse lócus entre ideários dominantes e oprimidos a escola precisa se efetivar enquanto espaço de diálogo aberto, uma vez que o aluno já traz consigo esses contrapontos do meio social em que está inserido, e é papel da mesma provocar a discussão, claro, de forma imparcial.

Daher (2017, p. 3) elucida bem essa discussão quando aponta que "no convívio social, a aquisição de conhecimento, apesar de constante, é incompleta em formar o indivíduo para vivência em sociedade. Ela é complementada pelo processo de ensino e aprendizagem desenvolvido no convívio escolar”. Nogaro e Francio (2009) complementam que a relação da escola com o universo de fora é complexa e não há como se pensar numa instituição educacional sem levar em consideração o contexto na qual está inserida.

E a partir dessas visões, consegue-se entender de forma clarificada o papel que a escola tem na formação de ideários sociais, mormente no que tange ao discurso de gênero e orientação sexual, para que a mesma não caia na falácia de perpetuar um discurso excludente e que não representa a maioria, sendo esta corporeificada por uma diversidade de posicionamentos que não pode se resumir a um único conglomerado hegemônico que se esquece da diversidade que permeia o ser humano, seja como ele se enxerga perante o espelho ou à sociedade ou como este se relaciona na sua afetividade. 
Assim, uma vez que gênero e sexualidade perpassam a constituição do ser humano, não se pode conceber que essas temáticas sejam assujeitadas à ideologias dominantes e encapsuladoras vigentes na ordem social, que reduzem os modos de ser e o relacionar-se afetivamente com o outro a padrões hegemônicos que não abarcam a totalidade, desta forma, o exercício de sair fora da caixa e enxergar a realidade, sem viseiras que impedem uma visão global de homem nas suas múltiplas formas de ser e estabelecer relações entre pares, precisa ser trabalhado e repensado dentro dos muros da escola.

Os fatores externos, o que o aluno traz consigo de experiência de vida e as bases conceituais de sua constituição ontológica não devem anulados pelo discurso educacional, pelo contrário, que esse posicionamento ideológico do aluno a respeito de gênero e orientação sexual seja ponto de partida para que a escola se estabeleça como espaço de discussões de suma relevância social e não caia na insídia de recrudescer um discurso em favor da invisibilização desses conceitos, dentro de uma significação deturpada de ser, e que para, além disso, nem sequer promova esse embate, perpetuando o silenciamento de seus alunos no descobrimento de si mesmos e no seus ideários e percepções sobre como essas questões são e devem ser tratadas no espaço escolar.

\section{Considerações Finais}

Levantar questões como estas que foram debatidas nesse estudo se fazem necessárias e urgentes. Passar pelo âmbito da discussão é atitude que precisa fazer parte da cotidianidade da escola, uma vez que ao se constituir como ambiente formal de educação, carrega em seu bojo o dever não só para com a formação crítica e emancipadora dos sujeitos, mas também para sua humanização que acontece ao longo da existência de cada ser e que inseridos neste processo tendem a nominar de forma deturpada e por vezes acabam perpetuar conceitos e saberes excludentes se o agir da escola na condução do seu marco filosófico for comprometido com reprodução da ordem social vigente.

Nesse sentido, levando em consideração os travessões e as reticências que permeiam esse campo de discussão dentro da escola e como a mesma se coloca diante de questionamentos sobre identidade de gênero e orientação sexual, precisamos refletir sobre eles a partir de quais fatores se constrói seu imaginário social, pois essas temáticas, por vezes, são concebidas com grau de polemicidade, mas são necessárias de serem colocadas em discussão quando se trata da formação do ser humano em sua onilateralidade.

E essa reflexão não se dá num campo de harmonia e angelicalidade, ao contrário, se constrói e se materializa através da dialeticidade, no embate entre visões de mundo divergentes e na quebra de paradigmas perpetuados ao longo da história como sendo uma verdade única e irrefutável.

Se levarmos em conta que essa discussão se dá no campo da ciência, logo, é possível inferir, que não há verdade absoluta ou qualquer conhecimento que não seja transitório, assim, a tentativa de introdução do debate acerca de gênero e sexualidade na escola se faz justamente pela necessidade de não minimizar a existência fora da normatividade heterossexista e cisgênera, rompendo barreiras que se formaram com a perpetuação hegemônica de conceitos que servem a determinadas ideologias e preceitos que tendem a obliterar o verdadeiro sentido de se discutir gênero e sexualidade na sociedade e na escola, que, entre tantos outros, se dá na busca de formar sujeitos abertos à diversidade, que não reproduzam violências dos mais variados tipos para com aqueles que não escolheram ser quem são ou a quem destinam o seu afeto dentro de uma lógica fora do padrão social imposto e validado por amontoados de senso comum.

Assim, recomendamos esse trabalho, para aqueles que enxergam como necessário o debate sobre sexualidades e identidades de gênero dentro da escola, como sendo espaço de formação e conscientização a respeito da diversidade. Enxerguem esse pequeno estudo como um ponto de partida para questões que atinjam uma amplitude ainda maior, pois a pretensão aqui sempre esteve longe de esgotar-se na literatura, pelo contrário, uma breve panorâmica se fez e espera-se que com este pontapé inicial a temática deslindada consiga sair do adormecimento e silenciamento. 
Research, Society and Development, v. 10, n. 9, e49710918409, 2021

(CC BY 4.0) | ISSN 2525-3409 | DOI: http://dx.doi.org/10.33448/rsd-v10i9.18409

\section{Referências}

Brasil. Ministério da Educação. (2018). Base Nacional Comum Curricular. http://basenacionalcomum.mec.gov.br/.

Brasil. (1988). Constituição da República Federativa do Brasil de 5 de outubro de 1988. Brasília.

Butler, Judith. (2003). Problemas de gênero: feminismo e subversão da identidade. Civilização Brasileira.

Daher, A. F. B. (2017). Aluno e professor: protagonistas do processo de aprendizagem. http://www.campogrande.ms.gov.br/semed/wp-content/uploads/site s/5/ 2017/03/817alunoeprofessor.pdf

Godoy. A. S. (1995). Pesquisa qualitativa: tipos fundamentais. Revista de administração de Empresas, 35 (3), 20-29. https://www.scielo.br/j/rae/a/ ZX4cT GrqYfVhr7LvVyDBgdb/?lang=pt\&format=pdf

Guareschi, P. A. (2008). Ética e relações sociais entre o existente e o possível. Scielo. http://books.scielo.org/id/6j3gx/pdf/jacques-9788599662892-03.pdf

Guedes, M. E. F. (1995). Gênero: o que é isso. Psicologia, Ciência e Profissão. https://www.scielo.br/j/pcp/a/np6zGkg hWLVbmLtdj3Mcyw J/?lang =pt\&fo rmat=pdf

Jacó -Vilela, A. M., \& Sato, L. (2012). Diálogos em Psicologia Social. Scielo. http://books.scielo.org/id/vfgfh/pdf/jaco-9788579820601.pdf

Jesus, J. G. de. (2012). Orientações sobre identidade de gênero: conceitos e termos. (2a ed.).

Lei n. 9394, de 20 de dezembro de 1996. (1996). Estabelece as Diretrizes e Bases da Educação Nacional. Diário Oficial da União.

Libâneo, J. C., Oliveira, J. F., \& Toschi, M. S. (2012). Educação escolar: políticas, estrutura e organização. (10a ed.). Cortez.

Louro, G. L. (2008). Gênero e sexualidade: pedagogias contemporâneas. Pró-posições, 19 (2), 17-23. http://www.scielo.br/pdf/pp/v19n2/a03v19n2.pdf

Martins, J. (2010). A pesquisa qualitativa. In FAZENDA, I. (Org). Metodologia da pesquisa educacional. (12a ed.). Cortez.

Mendes, W. G., \& Silva, C. M. F. P. da. (2020). Homicídios da População de Lésbicas, Gays, Bissexuais, Travestis, Transexuais ou Transgêneros (LGBT) no Brasil: uma Análise Espacial. Ciência e saúde coletiva, 25 (5), 1709-1722. https://prceu.usp.br/wp-content/uploads/2021/03/Homicidios-da-Populacao-deLesbicas-Gays-Bissexuais-Travestis-Transexuais-ou-Transgeneros-LGBT-no-Brasil-uma-Analise-Espacial.pdf

Miskolci, Richard. (2012). Teoria queer: um aprendizado pelas diferenças. Belo Horizonte: Autentica Editora: UFOP - Universidade Federal de Ouro Preto.

Mott, L., \& Cerqueira, M. (2003). Matei porque odeio gay. Grupo Gay da Bahia.

Nogaro, A., \& Francio, L. E. C. (2009). Por dentro da escola: contradições vividas por professores e alunos na cultura da incerteza. Revista de Ciências humanas. http://revistas.fw.uri.br/index.php/revistadech/article/download/390/702

Nogueira, D. M. (2010). Gênero e sexualidade na educação. Website do Grupo de Pesquisa Gênero, Corporalidades, Direitos Humanos e Políticas Públicas (GEPOP). http://www.uel.br/eventos/gpp/pages/arquivos/2.DanielaNogueira.pdf

Orientações Curriculares Nacionais para o Ensino Médio - Linguagens, códigos e suas tecnologias. (2006).

Pupo. K. (2007). Questão de gênero na escola. Portal do Ministério da Educação. http://portal.mec.gov.br/seb/arquivos/pdf/Etica/20_pupo.pdf

Rosa, J. G. (2019). Grande sertão: veredas - “O diabo na rua, no meio do redemoinho...”. (22a ed.). Companhia das Letras.

Severino, A. J. (2007). Metodologia do trabalho científico. (23a ed.). Cortez.

Silva, A. K. L. S. da. (2013). Diversidade sexual e de gênero: A construção do sujeito social. Revista NUFEN [Online], 5(1), 12-25. http://pepsic.bvsalud.org/pdf/rnufen/v5n1/a03.pdf

Silva, J. C., Maraschin, A. de. A., Funari, C. A., Mello, E. M. B., \& Junqueira, S. M. da. S. (2020). Gênero e sexualidade na BNCC: uma análise sob a perspectiva freireana. Revista Diversidade e Educação, 8 (2), 152-176. https://periodicos.furg.br/divedu/article/view/12104/8470

Silva, M. F. R. (2014). Gênero e sexualidade: práticas pedagógicas na escola. Monografia, UEPB. Guarabira, Paraíba, Brasil. 